\title{
O ENSINO REMOTO EMERGENCIAL E O USO DE RECURSOS DIGITAIS EM AULAS DE LÍNGUA INGLESA
}

\author{
Elaine Maria Santos ${ }^{1 \times}$ \\ ${ }^{1}$ Universidade Federal do Sergipe, São Cristovão, SE, Brasil
}

\begin{abstract}
Resumo
O presente artigo tem o objetivo de analisar o modo pelo qual os recursos digitais planejados para um curso de graduação em Letras PortuguêsInglês foram recebidos pelos discentes da UFS, em um cenário de pandemia. A pesquisa foi baseada na pesquisa-ação, com a análise do planejamento, ação, observação e reflexão do que foi desenhado para o curso, bem como do que foi avaliado pelos alunos, com o levantamento de algumas reflexões capazes de nortear futuras práticas. Foi possível, assim, perceber que os alunos conseguiram identificar a interatividade proposta com os recursos utilizados e creditaram à essa interatividade o sucesso alcançado ao final do curso, destacando, no entanto, que, mesmo promissores, esses resultados ainda estão muito distantes do que já havia sido verificado com o ensino presencial.

Palavras-chave: Ensino Remoto Emergencial, Recursos Digitais, Língua Inglesa
\end{abstract}

\section{EMERGENCY REMOTE TEACHING AND THE USE OF DIGITAL RESOURCES IN ENGLISH LANGUAGE CLASSES}

\begin{abstract}
This article aims to analyze the way in which the digital resources planned for an undergraduate course in Portuguese-English Language were received by the students from UFS, in a pandemic scenario. The research was based on the assumptions of action research, with the analysis of planning, action, observation and reflection of what was designed for the course, as well as what was applied and evaluated by students, with the analysis of some reflections capable of guiding future practices in this teaching modality. It was possible, therefore, to realize that the students were able to identify the proposed interactivity with the resources used and credited to this interactivity the success achieved at the end of the course, highlighting, however, that, even promising, these results are still
\end{abstract}

\footnotetext{
* Docente na Universidade Federal de Sergipe (UFS). Licenciada em Letras Português-Inglês, mestre em Letras e doutora em Educação pela Universidade Federal de Sergipe. Foi Professora Visitante na New York University, pela Fulbright, em 2018, e é a atual Coordenadora Nacional da Rede Andifes IsF - Inglês. Atua nas áreas de Língua Inglesa, Formação de Professores, Internacionalização, Política Linguística e História da Educação. E-mail: elainemaria@academico.ufs.br. Orcid: https://orcid.org/0000-0001-6376-2932.
} 
far from what they have already had been experienced with face-to-face teaching.

Keywords: Emergency Remote Teaching, Digital Resources, English Language 


\section{Introdução}

O ensino de línguas baseado na era do Pós-método prevê um processo de desenvolvimento de autonomia de professores e alunos, de modo que, diante de uma análise das necessidades dos discentes, do currículo a ser abordado e dos conhecimentos e experiências docentes, o professor possa teorizar a partir das práticas empregadas e aplicar atividades e práticas baseadas na teorização feita pelo professor, a partir do contato com a turma e os resultados obtidos, conforme destacado por Kumaravadivelu (2001). Diante das práticas desenvolvidas pelos professores, é importante pensar o papel e o espaço ocupado pelas Tecnologias Digitais da Informação e Comunicação (TDIC) no planejamento e execução das aulas dos professores de língua inglesa, levando em consideração as possibilidades, potencialidades, desafios e dificuldades encontradas.

Nesse momento em que enfrentamos a Pandemia pelo COVID19, as discussões sobre o uso das TDIC ganharam novos rumos, em decorrência da excepcionalidade das práticas vivenciadas, e da necessidade em se pensar em soluções educacionais que pudessem atender aos alunos de forma remota. $\mathrm{O}$ uso de recursos digitais se tornou obrigatório, mesmo entre aqueles que tinham pouco letramento digital ou que não tinham clareza sobre a importância desses recursos para o processo de ensino-aprendizagem. Sem tempo para estudos teóricos, planejamentos estratégicos ou treinamentos aprofundados, atividades foram criadas, com interação limitada e, mesmo quando diante de um Ambiente Virtual de Aprendizagem (AVA), observou-se, em muitos casos, um desconhecimento sobre potencialidades e usos durante a fase de preparação de aulas.

Diante do exposto, o presente artigo tem como objetivo analisar o modo pelo qual os recursos digitais foram utilizados em uma disciplina do curso de graduação em Letras Português-Inglês da Universidade Federal de Sergipe (UFS), investigando a relação entre planejamento, expectativas de alunos e professor, execução das atividades planejadas e feedback discente. Para que esse estudo possa ser mais efetivo, é importante fazer uma análise inicial sobre as diferenças entre ensino online e ensino remoto emergencial, bem como sobre o papel dos recursos digitais para o estabelecimento de um espaço educacional que oportuniza o letramento digital para professores e alunos, levando em consideração os limites impostos pela pandemia e as possibilidades de execução diante desse contexto atípico e emergencial. Essa investigação está situada metodologicamente na pesquisa-ação, já que o investigador é, ao mesmo tempo, participante e sujeito crítico da pesquisa e, as situações delimitadas são objeto de análise crítica, podendo acarretar em futuras mudanças de prática (CORNWELL, 1999). Paltridge e Phakiti (2015) complementam que, a partir de um roteiro que envolve planejamento, ação, observação e reflexão, a pesquisa-ação se caracteriza como um processo exploratório, com a possibilidade de gerar decisões, a partir do estabelecimento de questões chaves, que envolverão ações e desafios. 
Ensino online, ensino remoto e ensino presencial: aproximações e afastamentos

A Pandemia pelo COVID19, que assolou o mundo desde o final de 2019, mudou os rumos da sociedade, mexendo com nossos valores, com o modo pelo qual nos relacionamos com amigos, familiares e colegas de trabalho, com o medo do inesperado e como interagimos em sala de aula, levando-nos, inclusive, a uma reflexão sobre o que é uma sala de aula.

Diante da necessidade de distanciamento social e de respeito às medidas recomendadas pela Organização Mundial da Saúde, o mundo precisou redefinir vários conceitos, como, por exemplo, o de educação. A necessidade de quarentena fez com que pensássemos que bastava apenas, após algumas semanas, ou poucos meses, retomar as aulas e continuar com o planejamento anteriormente feito, o que não foi verificado na prática, já que o ano de 2020 foi marcado quase que exclusivamente pelo ensino remoto, e o mesmo destino parece se desenhar para 2021.

Inicialmente, é importante destacar que Ensino Remoto Emergencial (ERE) não é sinônimo de Ensino Online, também chamado de Educação online ou Educação a Distância (EaD). Hodges et al. (2020) salientam que essa modalidade de ensino é totalmente diferente da $\mathrm{EaD}$, uma vez que, por ter sido estabelecida em uma situação atípica e emergencial, não foi precedida de uma fase de planejamento, no qual são estabelecidos o AVA, recursos digitais, metodologia de ensino, sistema avaliativo e interações entre os atores envolvidos. Ao contrário, no ERE, as atividades começaram a ser transpostas a partir do que se tinha de práticas presenciais, de forma, muitas vezes, desordenada, sem que o acesso ao aluno fosse assegurado ou igualmente planejado, já que, no $\mathrm{EaD}$, ao fazer a inscrição, o aluno entra em contato com o projeto do curso e se predispõe a seguir os requerimentos exigidos. Em decorrência do caos educacional que foi implantado, foi comum nos depararmos com o acompanhamento do ERE a partir de blogs, por atividades enviadas por e-mail e, até mesmo, por WhatsApp. Soluções criativas passaram a ser colocadas em ação, na tentativa de se conseguir respostas às demandas que surgiam em decorrência da crise instaurada. Nem todas as soluções se mostravam eficazes e nem todas as demandas puderam ser atendidas, já que, o caráter emergencial fez com que muitas das atividades fossem meras reproduções de apostilas e PowerPoints anteriormente preparados, sem uma preocupação com a interatividade que poderia ser alcançada, a partir dos recursos digitais utilizados. Dessa forma,

postar apenas textos em pdf, apresentações de slides lineares, videoaulas e ou pirotecnias descontextualizadas é subutilização do digital em rede e instrucionismo curricular. Precisamos engendrar uma teia complexa de conexões e acionar os estudantes a adentrarem os conteúdos, produzindo colaborativamente conhecimentos nas interfaces de comunicação síncronas e assíncronas. Só assim, teremos educação online (SANTOS, 2020, p. 2) 
O caráter temporário, segundo Hodges et al. (2020), também deve ser levado em consideração ao nos debruçarmos sobre a sua análise, o que significa que, tão logo seja sanado o problema que levou a sociedade a seguir esse tipo de ensino, as práticas implementadas serão substituídas. Arruda (2020) complementa, destacando a importância no estabelecimento desses espaços educacionais proporcionados pela ERE, de modo que o contato entre aluno e escola possa ser reestabelecido e o suporte emocional seja também assegurado, já que a escola é um espaço de discussão dos problemas sociais que afligem a comunidade e que auxilia os alunos no estabelecimento de um pensamento crítico-reflexivo. Santos (2020) também ressalta os vínculos afetivos que são fortalecidos e o sentimento de pertença que é criado como vantagens do ensino remoto emergencial, mesmo quando as práticas educacionais desenvolvidas não atingem os resultados almejados. A autora destaca, no entanto, que esse ganho nem sempre é valorizado pelos professores, principalmente quando colocamos na ponta do lápis as situações que acabam sendo excludentes ou não democráticas, como os problemas de conexão e as dificuldades nas interações face-a-face.

O distanciamento físico e, até mesmo, virtual, que é encarado pelo professor se constitui em uma barreira e uma dificuldade a ser trabalhada pelo docente, não somente em decorrência dos problemas de aprendizado que podem ser observados e a sua tentativa em buscar soluções que possam auxiliar os alunos, mas, também, em consequência da diminuição da interatividade na aula. Sem o tempo devido para planejamento, políticas públicas eficazes de democratização do acesso a aparelhos e dados para conexão, e dificuldades por parte dos alunos em encontrar um espaço físico adequado aos estudos, o professor, principalmente o universitário, ainda encontra dificuldades nos momentos síncronos, caracterizados, muitas vezes, pela solidão imposta pela interlocução com câmeras desligadas e microfones nem sempre ativos de alunos que, mesmo querendo intensificar as trocas com o professor, não conseguem superar as dificuldades técnicas.

\section{O uso de recursos digitais nas práticas vivenciadas na pandemia no Ensino Superior}

Quando discutimos questões relacionadas ao ensino de línguas e ao uso das TDIC, estamos nos referindo não somente à disponibilização de computadores para os alunos da educação básica e superior e ao uso de aplicativos, mas, principalmente, a promover a discussão sobre os efeitos e os impactos do uso de dispositivos e recursos digitais durante o processo de ensino-aprendizagem de uma língua, de modo que os docentes possam planejar suas aulas e incluir os recursos que mais se encaixem aos objetivos propostos. Dessa forma, evitar-se-á a instauração de um modismo descompassado tanto com as necessidades dos alunos quanto com o planejamento feito, as possibilidades de uso, os objetivos traçados e os efeitos esperados. Essas questões já estavam sendo amplamente discutidas em eventos e periódicos científicos, que associavam discussões sobre práticas docentes, formação de professores e uso de tecnologias digitais. 
Com a pandemia, no entanto, e a ideia de que a educação não conseguirá ser restabelecida sem o suporte das TDIC, percebeu-se uma corrida por parte dos governos municipais, estaduais e federais, bem como dos corpos diretivos dos estabelecimentos de ensino para que professores sejam capacitados e comecem a utilizar dispositivos tecnológicos em suas aulas, com ênfase em plataformas e aplicativos, como se fosse o suficiente para que uma suposta normalidade fosse instaurada. Não basta um treinamento rápido sobre ferramentas digitais e Ambientes Virtuais de Aprendizagem se os professores continuam sem compreender o papel das tecnologias nas salas de aula e ainda não sabem como "transpor" as aulas anteriormente ministradas para essa nova modalidade de ensino, já que, sem a compreensão das potencialidades das TDIC, será corriqueira a busca por uma transposição de práticas. É possível, assim, afirmar que "problemas de infraestrutura e de formação docente deficitária são variáveis importantes que interferem diretamente em uma utilização crítica, intencional e produtiva das tecnologias" (RONDINI; PEDRO; DUARTE, 2020, p. 43).

Sem o planejamento adequado, oficinas temáticas e um projeto de formação continuada, esses docentes continuarão tendo muita dificuldade em tentar colocar em prática esses novos conceitos. Aliado a essa dificuldade, ainda temos alguns fantasmas a serem vencidos, como a falta de acesso a dispositivos, tais como notebooks, tablets e celulares, bem como problemas de conectividade, o que é comprovado por Arruda (2020, p. 266), amparado pelos dados atuais do PNAD/ IBGE, ao destacar que o ERE enfrenta uma grande dificuldade no ensino superior, em decorrência do "número significativamente reduzido de pessoas sem acesso às tecnologias digitais". Alunos e professores ainda precisam enfrentar problemas relacionados à dificuldade em se encontrar um espaço físico apropriado para as aulas e à necessidade de lidar com condições emocionais adversas, em um momento no qual a luta diária pela vida, durante a pandemia, é uma realidade. Assim, é importante lembrar que

a singularidade da pandemia deve levar também à uma compreensão de que a educação remota não se restringe à existência ou não de acesso tecnológico, mas precisa envolver a complexidade representada por docentes confinados, que possuem famílias e que também se encontram em condições de fragilidades em suas atividades. O ineditismo leva a ações que precisam envolver toda a complexidade da qual faz parte (ARRUDA, 2020, p. 266).

Ao analisarmos o contexto do ERE desenvolvido na Universidade Federal de Sergipe, pode-se afirmar que, anteriormente ao início do ensino, a instituição investiu em uma série de treinamentos sobre o uso do Google Classroom, do Moodle, de ferramentas de gravação e de conceitos relacionados ao ensino online, com ampla divulgação para toda a comunidade docente, de modo que os professores pudessem se inscrever nas várias turmas abertas para esse fim. No departamento de Letras Estrangeiras, foram desenvolvidas algumas oficinas para auxiliar o professor antes do início das aulas, com a colocação de alguns canais de 
comunicação entre professores e equipe especializada, durante todo o semestre, de modo que os docentes pudessem tirar as suas dúvidas. Durante os cursos, no entanto, ficou evidente a quantidade de dúvidas que ainda pairavam sobre os professores, com o acúmulo de conhecimentos e a dificuldade em processar todas as informações, incluí-las nos seus planejamentos e colocá-las em prática no semestre 2020.1, com início em 19 de outubro de 2020 e término em 12 de fevereiro de 2021.

Semanas de treinamento não são suficientes para que professores se sintam preparados para planejar e ministrar aulas na modalidade de ensino remoto, de modo que os resultados sejam positivos ou promissores. A frustração enfrentada pelos docentes é também responsabilidade das equipes responsáveis pela formação docente em tempos de pandemia, uma vez que os professores acabam se cobrando por resultados similares ao encontrados no ensino online, desconsiderando o fato de que o ERE não se assemelha ao $\mathrm{EaD}$, por não ter o mesmo planejamento, o mesmo suporte e o mesmo desenvolvimento. Hodges et al. (2020) se debruçaram sobre essa questão, sinalizando que

O tempo comum de planejamento, preparação e desenvolvimento para um curso universitário totalmente online é de seis a nove meses antes do curso ser entregue. $\mathrm{O}$ corpo docente geralmente se sente mais confortável ensinando na modalidade online na segunda ou terceira vez em que seus cursos online são ofertadas. É impossível para cada membro do corpo docente tornar-se repentinamente um especialista em ensino e aprendizagem online nesta situação atual, em que os prazos de entrega variam de um único dia a algumas semanas (HODGES et al., 2020, p. 7)ํ․

Aos poucos, professores e docentes começaram a perceber que não bastava apenas organizar os assuntos em aulas temáticas e postar as atividades síncronas e assíncronas, para que as interações anteriormente experimentadas no ensino presencial pudessem ser verificadas no ensino remoto. Uma das características do ensino online começou a fazer falta nas aulas remotas que eram ministradas: o desenho instrucional. A falta de um maior conhecimento do funcionamento do ensino online fez com que muitos professores se sentissem desmotivados por não conseguirem perceber um engajamento dos alunos para os encontros síncronos e para a realização das atividades propostas. Sem um planejamento que tenha em mente momentos de trocas entre professor e alunos e entre os alunos, faz com que o aluno se veja diante de um mero repositório de atividades isoladas que precisam ser respondidas dentro de um prazo de tempo pré-determinado, de modo que

ainda que se utilize uma única plataforma digital e se sigamos as mesmas orientações e diretrizes gerais, há desenhos didáticos mais instrucionais, em que docentes orientam estudos, leituras, tiram dúvidas de conteúdos e administram a agenda do sistema. Cada aluno faz suas tarefas, prestando conta das atividades quase sempre individualizadas. Isso é EAD. Alunos aprendem e se formam. [...]. Sendo assim, não é a materialidade do digital 
em rede que garante a educação online. O que a garante é o currículo que forjamos na mediação interativa e hipertextual da comunicação e da produção do conhecimento em rede (SANTOS, 2020. p.3)

Se a $\mathrm{EaD}$ é fundamentada e planejada a partir de um currículo que possa prever a mediação interativa e levando-se em consideração que o ERE não possui o planejamento necessário, nem muito menos o treinamento e suporte mínimos para que essa interação seja mediada, a busca de soluções paliativas para que o contato entre alunos e alunos e professor seja mais dinâmico e profícuo é um desafio de todos os docentes que tiveram que se submeter ao Ensino Remoto Emergencial e que ainda terão que passar por mais experiências como essas. Para que possamos visualizar o cenário educacional que se estabeleceu no ensino superior em 2020, em decorrência da pandemia do COVID19, vamos analisar o desenvolvimento do curso de Língua Inglesa VII, na UFS, analisando as fases de planejamento, execução de atividades, feedback e avaliação, lembrando que, conforme destacado por Hodges (2020), a avaliação deve receber uma atenção especial ao tratarmos do ERE, uma vez que ela precisa estar mais focada no contexto e no processo do que no produto propriamente dito, já que os meios de acesso ao ensino proposto pode não ter chegado a todos da mesma forma e no mesmo tempo.

\section{As experiências com recursos digitais em uma turma do ensino superior}

Para a análise do processo de planejamento de curso e de aulas, bem como de execução das atividades propostas e avaliação de resultados, parti do modelo defendido por Paltridge e Phakiti (2015), no qual a pesquisa-ação é desenvolvida a partir de procedimentos definidos que englobam os processos de planejamento, ação, observação e reflexão do objeto de pesquisa, no caso, o curso de Língua Inglesa VII, ministrado durante a pandemia do COVID19, na Universidade Federal de Sergipe, na modalidade de Ensino Remoto Emergencial, no semestre 2020.1, que englobou os meses de outubro de 2020 a fevereiro de 2021.

$\mathrm{Na}$ fase de planejamento da pesquisa, após a seleção da disciplina a ser analisada, no que se refere ao uso dos recursos digitais, na modalidade de ERE, procedeu-se ao processo de planejamento, com seleção de temáticas, de materiais, de recursos digitais, de processos avaliativos, de análise de feedback, de atividades assíncronas. Durante todo o semestre, as minhas percepções sobre as participações dos alunos, sobre o desempenho discente e o uso dos recursos digitais foram comparadas e contrastadas com as opiniões dos alunos, colhidas no feedback semanal e nas questões colocadas nos questionários das atividades assíncronas. Assim, a partir das observações feitas no decorrer do semestre, e das reflexões que perpassaram todo o processo, as ações foram replanejadas e reajustadas, para que os objetivos propostos para a disciplina pudessem ser alcançados.

Conforme o planejado inicialmente, o curso foi dividido em 15 encontros, de quatro horas cada, de modo que duas horas seriam ministradas de forma síncrona, pelo Google Meet, e duas como atividades assíncronas, com leituras e 
exercícios a serem resolvidos pelos alunos, conforme estabelecido em portaria publicada pela instituição. Por ser um curso de língua inglesa e, por sua natureza, pressupor momentos de interações entre pequenos grupos, era necessário encontrar soluções educacionais para que essas interações pudessem ocorrer, já que a divisão da turma em pequenos grupos ainda não é uma realidade da plataforma estabelecida pela IES. Para solucionar esse problema, auxiliei os alunos a acessarem o Microsoft Teams, também indicado pela universidade para auxiliar as aulas propostas. Criei uma sala de aula para turma, e dividi o grupo em 3 subequipes ou grupos. Assim, nos momentos de discussões, os alunos com dificuldade em acessar uma outra plataforma ficariam no Meet, enquanto que os demais seriam alocados nas três subequipes criadas.

A primeira preocupação na fase inicial do planejamento do curso foi sobre as condições de acesso dos alunos. Dos 22 alunos inscritos, apenas um aluno não respondeu ao questionário inicial do semestre. 57\% dos discentes sinalizaram ter um espaço adequado para as aulas síncronas, e $62 \%$ afirmaram não necessitar dividir o equipamento de acesso às aulas com outro membro da família, o que, ao mesmo tempo em que demonstrava que mais da metade dos alunos acompanhariam as aulas facilmente, deixava-me preocupada com os demais alunos, que enfrentariam mais dificuldades para acompanhar as aulas. $\mathrm{O}$ desconhecimento em relação à utilização das ferramentas do Google Classroom não se constituiria em um problema aparente, já que apenas 3 alunos informaram nunca terem acessado essa plataforma de ensino.

Cada aula foi dividida em algumas etapas. Inicialmente, uma atividade mais interativa, utilizando recursos digitais diversos, como vídeos, jogos e atividades preparadas em sites como o kahoot.com, wordwall.net e o baamboozle.com. A seguir, condução de atividades de vocabulário, leitura, compreensão auditiva, produção oral, escrita e/ou gramática foram colocadas em prática, com a utilização de recursos, tais como apresentações de PowerPoint, vídeos, imagens e áudios. Em praticamente todas as aulas foram inseridos momentos de discussão em pequenos grupos, utilizando as salas criadas no Microsoft Teams, com um retorno muito positivo dos alunos, já que nesses momentos havia maior interação dos alunos, uma vez que, cada grupo participava dos debates propostos, sem a intermediação ativa do professor, exercitando a autonomia necessária em aulas centradas nos alunos e em suas necessidades. Todas as aulas eram encerradas com uma breve discussão sobre o planejamento e execução das aulas, de modo que, por serem professores em formação inicial ou continuada ${ }^{2}$, não basta apenas trabalhar as questões linguísticas nas aulas de língua inglesa, separando-as das discussões metodológicas. O feedback e aproveitamento das aulas eram registrados tanto a partir das impressões coletadas com as falas dos próprios alunos durante às aulas, quanto com as respostas dadas nas atividades assíncronas e no questionário final de avaliação do curso. Esse feedback contínuo foi de grande importância durante esse processo, por ter norteado as ações de avaliação e (re)planejamento do curso.

Os alunos demonstraram não ter encontrado muitas dificuldades na resolução das atividades assíncronas propostas, já que, das 10 atividades 
cadastradas no Google Classroom, foi registrada uma média de 18 respondentes, sendo 21 o número total de alunos que conseguiram finalizar o curso. Este fato não chegou a ser surpreendente, já que os alunos relatavam, a cada aula, não ter dificuldades com o conteúdo ou com o sistema avaliativo, ponderando que as suas expectativas estavam sendo atendidas. Desde o início do curso, os discentes relatavam um contentamento pelo retorno das aulas, na modalidade remota, alegando a vontade em continuar os estudos, mas, também, a necessidade de um contato com a universidade, de modo que o retorno às atividades acadêmicas pudesse auxiliar nesse momento de incertezas e angústias trazidas pela pandemia do COVID19, conforme pode ser relatado pelos testemunhos destacados a seguir.

O retorno de atividades acadêmicas é para mim um aporte psíquico/ intelectual seguro, me afasta do ócio e reduz minha ansiedade (Discente 1). Muitos estudantes ficaram ociosos nesse período, creio que poder ter algo para dedicar suas energias, como o estudo, irá trazer benefícios a eles (Discente 2).

É uma distração a mais para não nos concentrarmos só no caos do mundo (Discente 3).

Começar a criar rotinas pode ajudar as pessoas que precisam de um senso de normalidade ou de organização em suas vidas (Discente 4).

Esse apoio aos alunos, no que se refere ao estabelecimento de uma rotina, destacado na pesquisa inicial de sondagem, foi retomado na avaliação final do curso, na qual os discentes destacaram que o contato com a universidade ajudouos no enfrentamento dos problemas trazidos pela pandemia. Muitos chegaram a afirmar que seus rendimentos foram superiores ao que havia sido imaginado, mesmo destacando que, com o ensino presencial, teriam tido um aproveitamento ainda melhor, o que está de acordo com o discutido inicialmente, já que o ensino remoto emergencial, por trazer soluções temporárias para uma rotina de estudos desenhada para ser presencial, não consegue atender todas as necessidades dos alunos, por não dispor de sistemas e recursos preparados para as suas necessidades e demandas. A satisfação com o curso pode ser comprovada com as respostas dadas pelos alunos sobre o aprendizado ao final do curso, de modo que, em uma escala de 1 a 6, na qual 1 sinaliza o nível mais baixo e 6, o nível mais alto, todos os alunos selecionaram os níveis de 4 a 6 , o que foi retificado com suas falas ao descreverem suas experiências na disciplina.

Considerei muito boa [a experiência] porem poderia ter sido ainda melhor se não fossem alguns problemas particulares (Discente 1).

Classifico como muito boa [a experiência] porque o ensino remoto permitiu utilizar com mais frequência ferramentas interativas. Claro que as dificuldades são muitas, principalmente no início do semestre com a adaptação à nova modalidade (Discente 4).

A experiência foi válida, porém, se tivesse a oportunidade de escolher entre ensino remoto e presencial, escolheria presencial. Meu rendimento seria melhor, mas, confesso que gostei muito dessa modalidade, principalmente 
do modo que a disciplina foi conduzida (Discente 5).

Pelo fato de estarmos em uma pandemia e tantas coisas ruins terem acontecido, tava tudo meio caótico, mas enquanto minha experiência, acredito que ultrapassou minhas expectativas. Foi maravilhoso! (Discente 6).

Conforme proposto inicialmente, o objetivo da pesquisa não foi somente $\mathrm{o}$ de avaliar a percepção dos alunos sobre a satisfação com a disciplina em questão, mas, principalmente, avaliar de que forma os itens destacados como essenciais contribuíram para o aprendizado, não somente a partir da minha percepção, como professora, mas, principalmente da percepção dos alunos. As seleções temáticas, de materiais, de recursos digitais e de processos avaliativos foram constantemente avaliadas a cada aula ministrada, uma vez que, conforme já detalhado, ao final de cada aula, nos minutos finais, as atividades empregadas eram avaliadas de forma oral, com a discussão sobre os objetivos de utilização e a opinião dos alunos sobre de que forma os procedimentos adotados contribuíram para o aprendizado.

Um dos pontos que considero como crucial nesse processo foi a efetividade das práticas destinadas ao desenvolvimento da oralidade, por se tratar de uma disciplina de língua inglesa, em uma modalidade de ensino na qual as práticas orais em pequenos grupos não é facilitada, com a utilização do Google Meet, que não prevê, ainda, a divisão do grupo em subgrupos de trabalho. Assim, orientei os alunos na utilização do Microsoft Teams, de modo que, em todas as aulas, teríamos um momento em que os alunos sairiam do Google Meet e acessariam os grupos criados em uma sala virtual específica para a turma. Como professora, poderia "visitar" cada grupo, auxiliá-los nas discussões propostas, dar algumas contribuições, e deixá-los discutindo um pouco mais, ou preparando algo a ser apresentado para todo o grupo. A necessidade em se buscar uma solução paliativa para trabalhar a oralidade venceu o receio em inserir mais uma outra plataforma, em um momento em que ainda estávamos nos inteirando sobre o modo pelo qual o ERE deveria ser conduzido. O feedback dos alunos foi crucial para o ajuste na frequência de utilização do Teams, na duração desses momentos e no tipo de atividades propostas, o que pode ser comprovado pelas falas dos discentes, destacadas abaixo.

Graças às estratégias tomadas pela professora, pude ter uma experiência boa. O uso do teams para as discussões foi a melhor parte. Muito bem elaborado e pensado. É uma pena que não pode ter sido melhor por conta da pouca participação dos alunos (Discente 2).

Confesso que participei muito menos no ensino remoto comparado ao ensino presencial. Enfrentei falta de motivação para as aulas e para as atividades. Senti que meus colegas passaram pelo mesmo, pois também não se engajavam nas aulas. As boas atividades, que foram feitas pelo teams, poderiam ter sido ainda melhores se nos estivéssemos motivados (Discente 4).

Minha maior dificuldade acredito que tenha sido não poder escolher sempre as pessoas com quem discutir em grupo, sempre tive dificuldades 
de socialização então acabou sendo um desafio em alguns momentos (Discente 7).

Momento da prática é fundamental, pois ajuda a compreender/ fixar melhor o conteúdo. Para mim, elas foram essenciais, acredito que sem elas eu teria uma percentual menor no quesito aproveitamento. \#ficaatividadesassincronas (Discente 8).

Apesar de terem sido propostos momentos de interação, alguns alunos sinalizaram problemas de motivação para essas atividades como empecilhos a serem superados, relacionando-os não necessariamente à disciplina, mas ao acúmulo de atividades assíncronas, de tarefas domesticas e de stress causado pela pandemia. A constatação de que as interações propostas não eram similares às verificadas no ensino presencial fez com que alguns alunos tivessem dificuldade em interagir, conforme relatado pelo discente 7 , ao sinalizar que não poder escolher com quem vai conversar dificulta os momentos de desenvolvimento da oralidade. Muitos estudantes também citaram os problemas de conexão como entraves a essas práticas, por não conseguirem uma conexão firme para ingressar nesses espaços.

Dos 17 alunos que responderam ao questionário final, 14 sinalizaram que os materiais utilizados foram interessantes e motivantes e nove alunos chegaram a afirmar acreditarem ter tido o mesmo rendimento que teriam com o ensino presencial, apesar de apenas 5 alunos terem sinalizado um contentamento com suas participações nas aulas. A participação, em muitos momentos, é maior por chat do que por voz, e poucas câmeras são ligadas durante a aula, o que foi justificado por cerca de $80 \%$ dos alunos como uma questão técnica, relacionada a problemas de conexão ou de barulho em casa. As interações proporcionadas nas aulas foram uma consequência de três tipos de ações: interações no Teams, conforme discutido anteriormente, atividades interativas a partir de alguns recursos digitais utilizados e os encontros virtuais que eles tiveram que ter, fora do horário da aula, para a preparação, em grupos (e posterior apresentação), de uma micro aula de 20 min sobre as temáticas trabalhadas nas aulas síncronas.

Os alunos tiveram a oportunidade de interagir entre si com o uso de recursos digitais já conhecidos, como atividades interativas criadas com o auxílio do PowerPoint, com respostas coletivas que deveriam ser dadas por formulários do Google Forms, após a apresentação de pequenos vídeos, participações no Microsoft Teams, além de atividades interativas criadas em sites especializados, tais como kahoot.com, wordwall.net e o baamboozle.com. O importante era promover a interação entre os alunos, de modo que a aula não se resumisse a uma palestra, seguida de exercícios a serem corrigidos pelo docente, e nem se resumisse a um roteiro de estudo individual, já que, segundo Santos (2020, p. 2), "A plataforma não deve ser apenas um repositório de conteúdos para trabalho individual e solitário, próprio do autoestudo". Ela deve prever situações de construção coletiva do conhecimento, partindo-se do pressuposto de que é muito mais fácil "aprender mais e melhor quando dialogar em rede e cocriar com outros docentes e estudantes com horizontalidade acadêmica e pessoal". Ao participar 
das atividades propostas no curso de Língua Inglesa VII, os alunos reconheceram o papel desses recursos e ferramentas. Dentre as falas destacadas pelos alunos, as seguintes podem ser utilizadas como exemplificação:

Classifico como muito boa [a experiência] porque o ensino remoto permitiu utilizar com mais frequência ferramentas interativas. Claro que as dificuldades são muitas, principalmente no início do semestre com a adaptação à nova modalidade (Discente 2).

Eu adorei o formato das atividades também no Google Formulários, dá pra interagir bastante fazendo upload de vídeos, imagens e etc. (Discente 6).

Apesar das dificuldades com o ambiente, com os aparelhos eletrônicos que utilizo e com o cansaço de toda a carga - física e emocional - que esse período trouxe, essa disciplina em especial foi bastante proveitosa para mim, principalmente por termos espaço para participar da aula. As aulas com participação mais ativa me mantém mais motivada do que as aulas que se transformaram em palestras, ainda que seja compreensível que haja mudanças e que estejamos em um período de adaptação. Meu aprendizado foi efetivo e tenho boas lembranças dessa disciplina, mas não do período como um todo (Discente 9).

A cada encontro, os alunos eram convidados a refletir sobre os pressupostos metodológicos e os objetivos que embasaram as aulas, o que os ajudaria na atividade final, já que eles haviam sido orientados, desde o início do curso, que deveriam, em grupo, preparar micro aulas sobre os assuntos trabalhados nas aulas síncronas. A partir das orientações detalhadas por Kumaravadivelu (2001), ao discorrer sobre o pós-método, as aulas preparadas não eram norteadas por uma metodologia ou abordagem específica. Partia-se sempre do pressuposto de que, com o conhecimento teórico e prático que o aluno em formação vem construindo durante a graduação, e tomando como base o fato de que esse professor em formação, ao contrário dos livros teóricos, conhece a sua própria turma, os planos de aula deveriam ser feitos a partir da análise das necessidades dos alunos, privilegiando as práticas indutivas, o conhecimento prévio dos alunos e a variedade de tipos de atividades.

Os vinte e um alunos foram divididos em 6 grupos de 4 ou 5 alunos, de modo que, ao final das apresentações, um feedback do professor era fornecido, com o registro posterior da nota nos sistemas. Os alunos avaliaram essa atividade como proveitosa, tanto em decorrência da interatividade conseguida, como pela oportunidade de utilizar os conhecimentos adquiridos em uma situação real de sala de aula. Oito alunos relataram, no questionário aplicado ao final do curso, que a oportunidade de apresentar micro aulas foi bastante positiva para o aprendizado deles, em oposição a apenas um aluno que não se colocou satisfeito com essa prática (os demais alunos não opinaram sobre esse quesito). Sete alunos complementaram a pergunta anterior, sinalizando que as micro aulas contribuíram para uma maior reflexão sobre as questões metodológicas discutidas em sala, enquanto que dois alunos não encontraram muito correlação entre esses dois pontos.

Como avaliação geral, os discentes se mostraram satisfeitos com a experiência do ensino remoto na disciplina Língua Inglesa VII, destacando, 
de forma quase unânime, que, apesar da dinamicidade das aulas, dos tipos de atividades empregadas, tanto de forma síncrona, como assíncrona, a sensação de aprendizagem ainda era inferior ao que verificavam no ensino presencial, reconhecendo que os ajustes feitos ainda não sanavam todas as dificuldades encontradas, especialmente ao considerar que o emocional de todos ainda estava abalado, em consequência da pandemia do COVID19 e das incertezas que esse momento vem trazendo.

\section{Algumas considerações}

O distanciamento social imposto pela pandemia do COVID19 mexeu com nossas dinâmicas diárias, não apenas no que se refere às práticas de higienização e uso de máscaras, como também às questões educacionais e de trabalho. Pensar na educação nesse novo contexto perpassa por questões não apenas relacionadas à filosofia educacional e à metodologia e práticas de ensino, como também ao apoio emocional e psicológico que alunos e professores passaram a necessitar. São muitos os relatos de cansaço e fadiga mental, em decorrência do aumento no número de reuniões, da busca por novas soluções educacionais e das incertezas trazidas pelo vírus.

$\mathrm{Na}$ análise proposta do curso de Língua Inglesa VII, conduzido na modalidade de Ensino Remoto Emergencial, na Universidade Federal de Sergipe, foi possível constatar o que autores como Arruda (2020) já tinham identificado: o ERE, além do caráter educacional, é visto pelos alunos como um suporte emocional e psicológico importante, em um momento em que o medo e o caos se instalaram, em decorrência das perdas trazidas pela pandemia.

Não podemos, no entanto, reproduzir práticas do ensino presencial nesse novo modelo de ensino, com a desculpa de que, pelo menos, estamos levando conhecimento para os alunos, porque as interações observadas não são as mesmas, a motivação para a aulas é muito variável e a participação do aluno é dificultada pelo medo que as tecnologias digitais de comunicação e informação ainda trazem nas universidades. Deparamo-nos com alunos que se conectam às suas aulas síncronas com câmeras desligadas e participação concentrada nos chats disponibilizados pelas plataformas utilizadas. A busca por mais interatividade, por parte do professor, não é uma garantia de sucesso, pois ainda está dependente da resposta dada pelos alunos. Na pesquisa aqui apresentada, os discentes sinalizaram que essas interações, conduzidas no Microsoft Teams, geraram motivação e foram importantes para o aprendizado, pois eles conseguiram interagir em pequenos grupos, de forma similar ao que acontecia nas aulas presenciais. Contudo, mesmo com a ciência dessa possibilidade e o reconhecimento dos ganhos, alguns alunos ainda resistiram em participar. Mesmo estando presentes nos subgrupos de discussão, algumas câmeras ainda permaneciam desligadas e, para alguns, o contato se restringia a poucas falas no chat.

Além das oportunidades de discussão levantadas pela professora no Teams, todos os alunos tiveram que apresentar micro aulas em grupos de quatro ou 
cinco alunos, com a obrigatoriedade de participação por parte de todos. Essa se constituiu na única prática obrigatória de fala e foi bem recebida pelos alunos, que sinalizaram a necessidade em se colocar algumas rotinas e atividades obrigatórias em grupo, ajudando-os a superar os seus medos e ansiedades.

Professores e alunos não serão os mesmos após as práticas verificadas durante o Ensino Remoto. As perdas de momentos de interação são esperadas, mas não podemos simplesmente utilizar esse fato como uma desculpa para a não utilização de recursos digitais interativos que possam diminuir a distância entre professor e aluno e fazer com o estudante consiga resgatar a sua voz em sala de aula, posicionando-se de forma crítica e expondo os seus pontos de vista. Como seres humanos, resistimos, muitas vezes, a situações em que mudanças extremas são necessárias, mas ao pensar no ensino de uma língua estrangeira como uma oportunidade de desenvolvimento linguístico e sócio-cultural do aluno, precisamos tentar, testar e experimentar novas práticas de modo que, mesmo ainda reticentes, os discentes possam participar de forma mais efetiva da aula.

Essa primeira experiência de ERE, com certeza, ajudou-me como professora e aluna, pois muitas atividades funcionaram e trouxeram a interação almejada, enquanto que, com outras, aprendi que a idealização de uma atividade não necessariamente repercute na execução conforme planejamento, já que, mesmo ciente da importância em pensarmos nas necessidades dos alunos, acabamos, em alguns momentos, percebendo que nossos perfis, estilos e experiências acabam prevalecendo. São nesses momentos que, como em todo processo de ensinoaprendizagem, paramos, refletimos, reavaliamos e replanejamos.

\section{Notas}

1. Typical planning, preparation, and development time for a fully online university course is six to nine months before the course is delivered. Faculty are usually more comfortable teaching online by the second or third iteration of their online courses. It will be impossible for every faculty member to suddenly become an expert in online teaching and learning in this current situation, in which lead times range from a single day to a few weeks (Texto original. Tradução do autor).

2. Para Silva (2014), os alunos de graduação podem ser enquadrados como participantes tanto de processos de formação inicial de professores quanto de formação continuada, quando levamos em consideração os treinamentos que esses alunos já tiveram nas experiências vividas como professor.

\section{Referências}

ARRUDA, Eucídio Pimenta. Educação remota emergencial: elementos para políticas públicas na educação brasileira em tempos de Covid-19. EmRede, v. 7, n. 1, p. 257-275, 2020.

BROOKS, C.; GRAJEK, S.. Faculty readiness to begin fully remote teaching. Educause Review, 2020. Disponível em: https://er.educause.edu/blogs/2020/3/facultyreadiness- to-begin-fully-remote-teaching. Acesso em: 10 de fevereiro de 2021.

CORNWELL, Steve. Interview with Anne Burns and Graham Crookes. The Language Teacher, vol. 23, no. 12, pp. 5-10, 1999. 
HODGES, Charles et al. The difference between emergency remote teaching and online learning. EDUCAUSE Review, 2020. Disponível em: https://er.educause. edu/articles/2020/3/the-difference-between-emergency-remote- teaching-andonline-learning, 2020. Acesso em: 20 de fevereiro de 2021.

KUMARAVADIVELU, B. Toward as postmethod pedagogy. TESOL Quarterly, v. 35, n.4, p. 537-560, 2001.

PALTRIDGE, Brian; PHAKITI, Aek. Research methods in applied linguistics: a practical resource. London: Bloomsbury Academic, an imprint of Bloomsbury Publishing Plc, 2015.

RONDINI, Carina Alexandra; PEDRO, Ketilin Mayra; DUARTE, Cláudia dos Santos. Pandemia da covid-19 e o ensino remoto emergencial: mudanças na prática pedagógica. Interfaces Científicas: educação. vol. 10 n. 1 - 2020.

SANTOS, Edméa. EAD, palavra proibida. Educação online, pouca gente sabe o que é. Ensino remoto, o que temos. Notícias, Revista Docência e Cibercultura, ago. 2020. Disponível em: https://www.e-publicacoes.uerj.br/index.php/re-doc/ announcement/view/1119. Acesso em: 20 de fevereiro de 2021.

SILVA, Paulo Roberto Boa Sorte. A graduação em letras-inglês como formação contínua: desfazendo unilateralidades. Tese (Doutorado em linguística aplicada e estudos da linguagem). Pontifícia Universidade Católica de São Paulo - PUC-SP, São Paulo-SP, 2014. 